\title{
ASPECTOS MORFOANATÔMICOS E FISIOLÓGICOS DE SEMENTES E PLÂNTULAS DE Amburana cearensis (FR. ALL.) A.C. SMITH (LEGUMINOSAE - PAPILIONOIDEAE) ${ }^{1}$
}

\author{
Marta Bruno Loureiro², Clarissa Abreu Santos Teles ${ }^{3}$, Ivana Oliveira Virgens ${ }^{4}$, Bárbara Rosemar \\ Nascimento de Araújo ${ }^{5}$, Luzimar Gonzaga Fernandez ${ }^{2}$ e Renato Delmondez de Castro ${ }^{2}$
}

\begin{abstract}
RESUMO - Os objetivos deste trabalho consistiram em descrever e ilustrar os aspectos morfoanatômicos de sementes e plântulas de Amburana cearensis, relacionando o desenvolvimento dos tecidos às fases de germinação das sementes, para verificar as mudanças que ocorreram durante esse processo. Os ensaios foram conduzidos no Laboratório de Estudos em Meio Ambiente da Universidade Católica de Salvador (LEMA/UCSal). O delineamento experimental utilizado foi o inteiramente casualizado com quatro repetições de 25 sementes por tratamento. A curva de embebição foi elaborada com base no peso fresco das sementes durante o processo de embebição, em períodos variando entre 0 e 318 h. Para análise morfológica das sementes e plântulas, ambas foram observadas a olho nu e ao microscópio estereoscópico, a fim de confeccionar a prancha. As secções anatômicas foram feitas com o auxílio do micrótomo rotativo, utilizando-se para tal as sementes durante as fases da germinação. Quanto à análise morfológica, as sementes são esternospermáticas e o embrião axial, sendo a germinação do tipo epígea e fanerocotiledonar. Quanto aos aspectos anatômicos, pôde-se verificar que as sementes de A. cearensis são bitegumentadas e exotestais e apresentam os cotilédones como principal tecido de reserva. O tegumento é composto por um estrato de macroesclereídes e por estratos de osteoesclereídes e possui compostos fenólicos, o que confere às sementes certo grau de dormência por impermeabilidade do tegumento, dificultando, assim, a absorção de água.
\end{abstract}

Palavras-chave: Amburana cearensis; Germinação; Morfologia; Anatomia.

\section{MORPHOLOGY, ANATOMY AND PHYSIOLOGICAL ASPECTS OF SEEDS AND SEEDLING OF Amburana cearensis (FR. ALL.) AC SMITH (LEGUMINOSAE - PAPILIONOIDEAE)}

\begin{abstract}
The present study aimed to describe and illustrate the morphology aspects of seeds and seedlings of Amburana cearensis linking the development of tissues to the stages of germination in order to verify the changes that occurred during this process. The tests were carried out at the Laboratory for Environmental Studies from the Catholic University of Salvador (LEMA / UCSal). The experimental design was a completely randomized with 4 replications of 25 seeds per treatment. The imbibition curve was based on seed fresh weight during imbibition at intervals varying between 0 and 318 hours. Naked eye and stereomicroscope observations were performed for the morphological analysis of seeds and seedlings and confection of botanical illustrations. The anatomical sections of seeds during the stages of germination were performed with a rotary microtome. A. cearensis seeds were classified as sternospermatics with an axial embryo and epigeal phanerocotylar germination.
\end{abstract}

\footnotetext{
${ }^{1}$ Recebido em 25.08.2012 aceito para publicação em 02.07.2013.

${ }^{2}$ Universidade Federal da Bahia, Instituto de Ciências da Saúde - Laboratório de Bioquímica, Biotecnologia e Bioprodutosl. Email:<brunoloureiro70@gmail.com>,<luzimargonzaga@gmail.com>e $<$ renatodel@gmail.com>.

${ }^{3}$ Mestre em Biotecnologia, Universidade Federal da Bahia, Salvador, BA, Brasil. E-mail:<cllari@gmail.com>.

${ }^{4}$ Doutoranda em Processos Interativos de Órgãos e Sistemas, Universidade Federal da Bahia. E-mail: ivanaovirgens@yahoo.com.br

${ }^{5}$ União Metropolitana para o Desenvolvimento da Educação e Cultura - Laboratório de Histologia (UNIME). E-mail:

$<$ brosemar@ig.com.br>.
} 
Seeds are bitegmic, exotestic and the cotyledons are the main reserve tissue. Seed coat is composed of a fairly rigid stratum of macrosclereides and strata of osteosclereides and phenolic compounds that confer a certain degree of seed dormancy due to tegument impermeability, hindering the absorption of water.

Keywords: Amburana cearensis, germination, morphology, anatomy.

\section{INTRODUÇÃO}

Os estudos que envolvem aspectos morfológicos de sementes e plântulas são fundamentais para facilitar o reconhecimento das espécies em estudos de regeneração natural (CRESTANA, 1998), podendo fornecer informações importantes na classificação taxonômica e considerações morfológico-evolutivas (OLIVEIRA, 2001; CUNHA; FERREIRA, 2003; MELO et al., 2004), nas análises e interpretação dos testes com sementes em laboratório e no reconhecimento da espécie em bancos de sementes do solo e em bancos de plântulas.

Os aspectos anatômicos de sementes têm sido investigados em várias espécies de diferentes famílias, a exemplo de Oneocarpus minor Mart. (Arecaceae), Tecoma stans (L.) Kunth (Bignoniaceae), Podocarpus sellowii Klotz (Podocarpaceae) e Styrax camporum (Styracaceae), entre outras (GARCIA et al., 2006; JULIO; OLIVEIRA, 2007; RENÓ et al., 2007; MENDONÇA et al., 2008). De acordo Oliveira (1999), a utilização de informações anatômicas tem-se tornado frequente, sendo de importância crucial em estudos taxonômicos e para a compreensão de vários fenômenos ligados ao comportamento/adaptação das espécies vegetais nos diferentes ecossistemas.

Entre os fatores do ambiente, a água é o fator que mais influencia o processo de germinação. Com a absorção de água, ocorre a reidratação dos tecidos e, consequentemente, a intensificação da respiração e de todas as outras atividades metabólicas, que resultam no fornecimento de energia e nutrientes necessários para a retomada de crescimento por parte do eixo embrionário (CARVALHO; NAKAGAWA, 2000).

O tegumento é um dos principais condicionantes da absorção de água pelas sementes e, consequentemente, da germinação, do vigor e da longevidade, sendo o estudo da sua estrutura e propriedades de grande importância para explicar o comportamento das sementes sob determinadas condições ambientais (SOUZA; MARCOSFILHO, 2001).

Revista Árvore, Viçosa-MG, v.37, n.4, p.679-689, 2013
Amburana cearensis (Fr. All.) A. C. Smith é uma espécie arbórea pertencente à família Leguminosae papilionoideae, sendo conhecida popularmente como amburana-de-cheiro, cumaru e cerejeira, entre outros nomes. A espécie ocorre naturalmente no Nordeste do país, no bioma Caatinga, nos Estados do Espírito Santo e Minas Gerais, na Floresta Pluvial do Vale do Rio Doce e nos afloramentos calcários e matas decíduas dos Estados de Mato Grosso, Goiás, Tocantins, Mato Grosso do Sul e São Paulo (LORENZI, 1992). É utilizada popularmente no tratamento de doenças, sendo as cascas do caule e as sementes usadas sob a forma de chá por apresentarem atividades anti-inflamatórias e espasmolíticas, além de serem utilizadas nos tratamentos da asma, tosse e bronquite (CANUTO; SILVEIRA, 2006). Pelas características descritas e por sua grande importância econômica para a Região Nordeste, a espécie tem sido amplamente extraída, sendo suas populações naturais reduzidas drasticamente, estando hoje na lista das espécies ameaçadas de extinção, na categoria em perigo, publicada pela IUCN.

Dessa forma, este trabalho teve como objetivo identificar as diferentes fases do processo de germinação de sementes de $A$. cearensis, bem como descrever e ilustrar os aspectos morfológicos e anatômicos de sementes e plântulas, relacionando o desenvolvimento dos tecidos nas fases de germinação das sementes, a fim de verificar as mudanças que ocorreram nos tecidos durante esse processo.

\section{MATERIAL E MÉTODOS}

\subsection{Coleta e armazenamento das sementes}

Os ensaios foram conduzidos no Laboratório de Estudos em Meio Ambiente, da Universidade Católica do Salvador (LEMA/UCSal), e no Laboratório de Histologia da União Metropolitana para o Desenvolvimento da Educação e Cultura Ltda. (UNIME). As sementes de $A$. cearensis foram cedidas pelo Banco de Germoplasma da Empresa Brasileira de Pesquisa Agropecuária/Centro de Pesquisa Agropecuário do Trópico Semiárido (EMBRAPA/CPTSA). Após a coleta 
e o beneficiamento, as sementes permaneceram armazenadas em câmara climatizada sob a temperatura média de $7^{\circ} \mathrm{C}$ e $50 \%$ de umidade relativa até o início dos testes.

\subsection{Morfologia de sementes e plântulas de A. cearensis}

A análise morfológica das sementes foi realizada com o auxílio de microscópio estereoscópico binocular, sendo observados os detalhes externos e internos, registrando-se características, como consistência, pilosidade, brilho e coloração para a posterior confecção das pranchas. A metodologia e terminologia empregadas, assim como os parâmetros utilizados para as descrições, foram baseadas em Amorim et al. (1997), Barroso et al. (1999) e Cunha e Ferreira (2003).

As medidas biométricas foram tomadas com o auxílio de paquímetro digital Marathon com precisão de $0,01 \mathrm{~mm}$, em quatro repetições de 25 sementes, registrando-se comprimento, largura e espessura, a fim de determinar o tamanho médio das sementes.

Para o estudo morfológico das plântulas, as sementes foram semeadas em copos plásticos descartáveis com capacidade para $200 \mathrm{~mL}$, contendo $50 \mathrm{~g}$ de vermiculita esterilizada e dispostos em estantes de sala de crescimento ajustada à temperatura média de $25^{\circ} \mathrm{C}$ e fotoperíodo de 12 h/luz. Em seguida, as plântulas em diversos estádios de desenvolvimento foram analisadas, descritas, fixadas em formaldeído 50\% (FAA) e, posteriormente, desenhadas para a confecção das pranchas. A terminologia empregada e os parâmetros utilizados nas descrições basearam-se em Ducke (1965; 1969), Radford et al. (1974), Kuniyoshi (1983), Stern (1992), Oliveira (1993), Barroso et al. (1999) e Raven (1999). O delineamento experimental utilizado foi o inteiramente casualizado com 50 repetições.

\subsection{Curva de embebição de sementes de $A$. cearensis}

O delineamento experimental utilizado foi o inteiramente casualizado com quatro repetições de 25 sementes por tratamento, em esquema fatorial $2 \times 25$, sendo os tratamentos constituídos pelos 25 períodos de embebição $(0,6,12,18,24,30,36,42,48,54,60$, $66,72,84,96,108,120,144,168,192,222,246,270$, 294 e 318 h) em sementes com e sem escarificação. Inicialmente, as sementes sofreram ou não escarificação do lado oposto ao hilo, a fim de promover maior uniformidade na germinação das sementes. Em seguida, foram dispostas em rolo de papel umedecido com água destilada em volume equivalente a três vezes o peso do substrato e incubadas em câmara tipo B.O.D. ajustada na temperatura de $25 \pm 1{ }^{\circ} \mathrm{C}$, sob a ausência de luz, de acordo com as recomendações de Brasil (1992). Após cada período de embebição, as sementes foram pesadas em balança de precisão para a elaboração da curva de germinação, sendo registrado, além do peso, o número de sementes que emitiram a raiz, estas consideradas como germinadas. Após a finalização do teste, os dados foram submetidos às análises de variância e de regressão, com o auxílio do programa SISVAR (Versão 5.0).

\subsection{Aspectos anatômicos da germinação de sementes de A. cearensis}

Com base nos resultados da curva de germinação para sementes de $A$. cearensis, foram selecionados os períodos correspondentes às fases I, II e III da curva de embebição, a fim de se observarem as mudanças que ocorreram nos tecidos das sementes durante esse processo.

Para tal, inicialmente as sementes sofreram desponte do lado oposto ao hilo. Foram postas para embeber em água destilada e retiradas nos períodos $0,12,24$, 72, 96 e 112 h de embebição. Após cada período de embebição, as sementes foram imediatamente fixadas

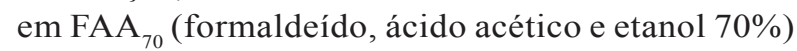
durante sete dias, a fim de bloquear o metabolismo das células. Após esse processo, foram conservados em etanol $70 \%$ até o início do emblocamento. Para este foi utilizada a metodologia proposta por Kraus e Arduin (1997), modificada.

Os cortes anatômicos foram realizados com o auxílio de um micrótomo rotativo da marca LEICA RM2125RT, a coloração foi realizada com safranina $1 \%$ em etanol $70 \%$ e azul de alcian $1 \%$ em etanol $50 \%$, conforme metodologia de Kraus e Arduin (1997), modificada, e as lâminas permanentes montadas em bálsamo-docanadá. Para os testes histoquímicos, sementes frescas foram cortadas transversalmente à mão livre, sendo em seguida realizadas as reações com lugol para detecção de amido e cloreto férrico, para identificação de compostos fenólicos (KRAUS; ARDUIN, 1997).

A leitura das lâminas foi realizada com o auxílio de microscópio binocular (Nikon Eclipse E 600), e as imagens obtidas através de fotomicrografias realizadas com câmera fotográfica (Nikon FDX-35), acoplada ao microscópio.

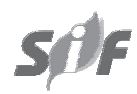

Revista Árvore, Viçosa-MG, v.37, n.4, p.679-689, 2013 


\section{RESULTADOS E DISCUSSÃO}

\subsection{Morfologia de sementes e plântulas de $A$. cearensis}

De acordo com a análise biométrica, as sementes de Amburana cearensis apresentaram, em média, 14,4 mm de altura, 10,4 $\mathrm{mm}$ de largura e 4,7 $\mathrm{mm}$ de espessura. Sendo a semente, segundo a classificação de Beltrati (1992), estenospérmica, com a forma variando entre elíptica, oblonga e ovoide, de acordo com Gunn (1981). O tegumento apresenta textura lenhosa, sendo a testa de coloração marrom e opaca, o hilo bem visível, de formato elíptico, localizado lateralmente próximo à base da semente, numa região mais escura e proeminente. A calaza localiza-se acima do hilo e é pouco perceptível, e a micrópila localiza-se numa protuberância abaixo do hilo (Figura 1A).

O embrião é axial, invaginado, com cotilédones variando de forma ovoide, elíptica a oblonga, planos, carnosos, amarelados, lisos, com ápice arredondado e base obtusa. O eixo hipocótilo-radícula é infletido, cônico, curto, articulado entre os lóbulos dos cotilédones, e o polo radicular é mais externo à semente (Figura $1 \mathrm{H}$ ).

A germinação tem início com a emissão da raiz primária que rompe o tegumento na base da semente, próximo ao hilo aproximadamente cinco dias após a semeadura. De acordo com os resultados, a germinação é do tipo epígea e a plântula, fanerocotiledonar, pois durante a germinação seus cotilédones são elevados acima do nível do solo e expandem-se, liberando o tegumento (RAVEN, 1999). Araiz primária que inicialmente apresenta coloração bege amarronzada é sinuosa, cilíndrica, e apresenta pêlos simples, pouco visíveis e esparsos, de coloração branca, a coifa é esbranquiçada, clara e pubescente (Figura 1BC). Posteriormente, a raiz adquire coloração amarelo-clara, tendo, então, início a formação das raízes secundárias.

Os cotilédones apresentam coloração amareloclara, são envolvidos pelo tegumento, tem consistência carnosa e função de reserva antes da sua exposição. A partir do estádio no qual rompem o tegumento, são opostos, unilaterais, isófilos, adquirindo coloração verde, tornando-se, então, fotossintetizantes, com bordos inteiros e sem nervação, passando de subsésseis a curto-peciolados.

O epicótilo é visível a partir do $8^{\circ}$ dia de semeadura, apresentando inicialmente coloração amarelada, formato cilíndrico, superfície lisa e brilhante. A partir da fase de formação dos protófilos, o epicótilo adquire coloração verde claro e densa pilosidade, com pêlos esbranquiçados. Os catáfilos ficam inseridos na porção mediana do epicótilo, sendo sésseis com formato lanceolado (Figura 1F).

Os protófilos são opostos, pinaticompostos, imparipenados e curto-peciolados, com três a cinco folíolos. Os folíolos são discolores, curto-peciolados, elípticos, com margem inteira, ápice agudo, base obtusa e consistência membranácea. Apresentam-se pilosos e com nervação peninérvea evidente na face abaxial. A gema apical apresenta-se bem desenvolvida desde o início da germinação e pode ser vista quando se promove a abertura dos cotilédones. O metáfilo surge cerca de 30 dias após o início da germinação e se apresenta com folíolos alternos e imparipenados, com sete a nove pinas.

As raízes de consistência herbácea apresentam, no estádio de plântula, sistema radicular pivotante com raiz primária axial, sublenhosa, estriada, glabra, mais espessa na base e afilada no ápice (Figura 1G). Cunha e Ferreira (2003) observaram que, após 116 dias de germinação, a raiz principal de $A$. cearensis sofreu espessamento, formando uma tuberosidade. De acordo Labouriau (1964), a presença de raiz tuberosa torna a espécie capaz de resistir às condições adversas do meio e, segundo Rizzini (1965), tal estrutura se constitui em estratégia adaptativa, pois tais raízes apresentam alto poder de rebrotamento quando ocorrem danos na parte aérea.

De acordo com a classificação de Miquel (1987) A. cearensis apresenta germinação do tipo semi-hipógea fanerocotiledonar, com os cotilédones carnosos

\subsection{Curva de embebição de sementes de $A$. cearensis}

Pode-se verificar que houve diferença entre as curvas para sementes escarificadas e não escarificadas. Analisando a curva de embebição para sementes que sofreram escarificação, pode-se verificar o padrão trifásico de acordo com o modelo proposto por Bewley e Black (1994). Nessas sementes, a fase I foi registrada entre os períodos de 0 a $60 \mathrm{~h}$, caracterizada pela rápida absorção de água, com significativo aumento no peso das sementes. No período de 60 a 84 h, verificou-se a fase II, em que, de acordo com Bewley e Black (1994), a absorção de água se dá em níveis baixos, sendo este o momento em que a semente adquire condições físico- 
(A)

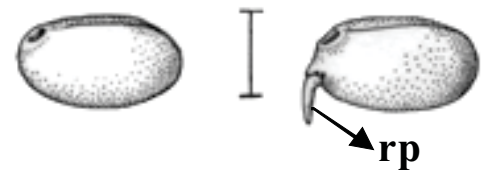

(H)

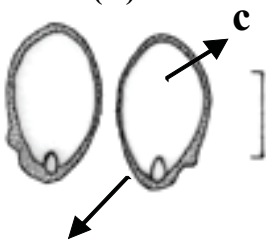

ex
(B)

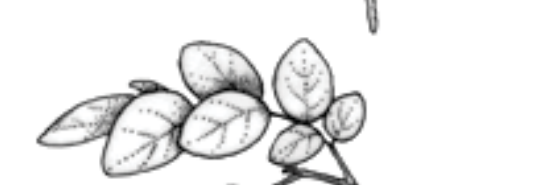

(C)

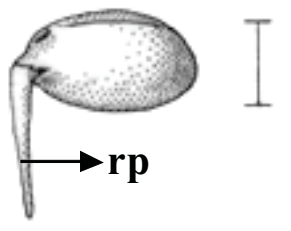

(D)

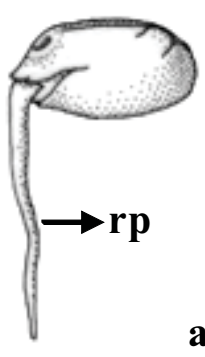

al

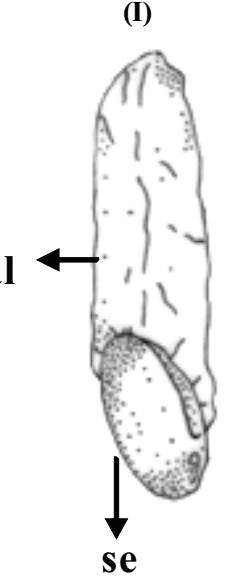

(I)
(E)

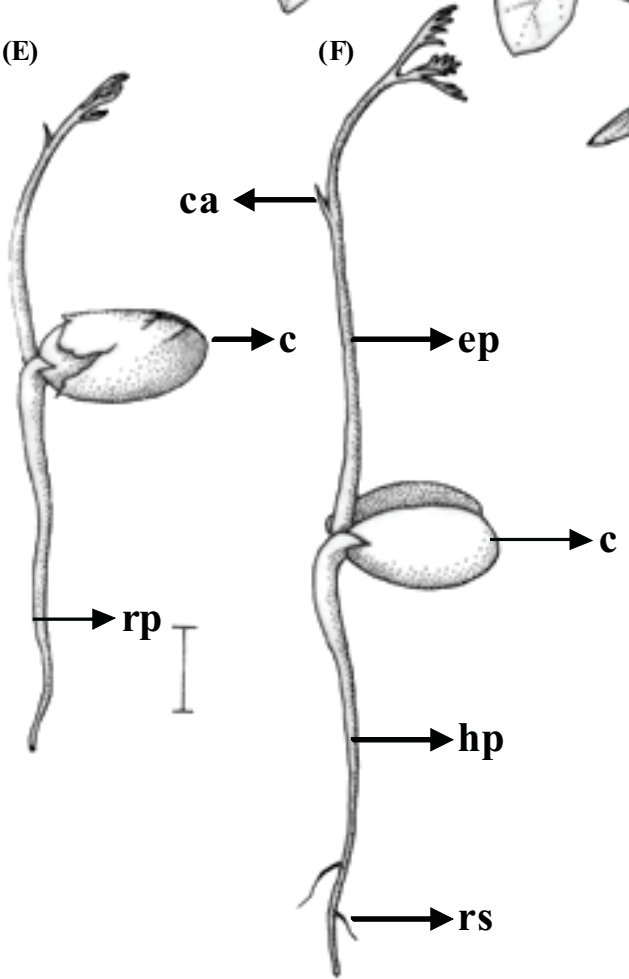

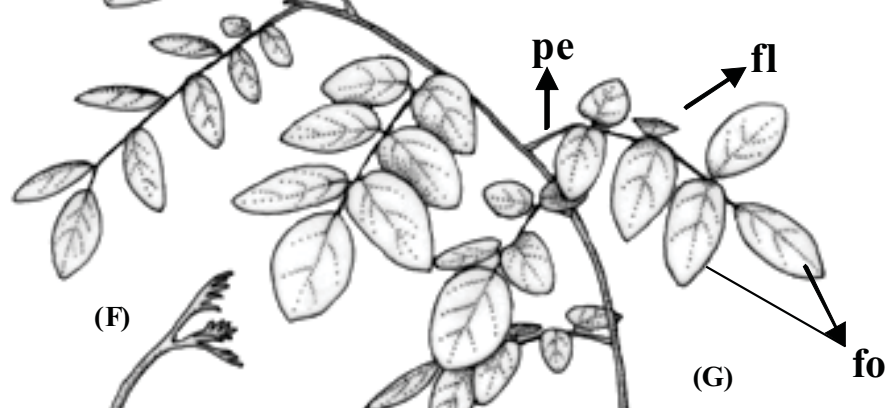

(G) fo

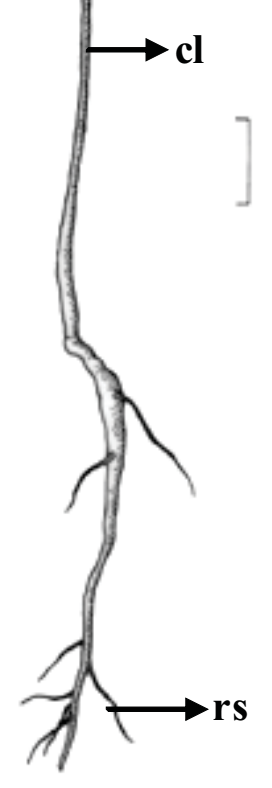

Figura 1 - Aspectos morfológicos da semente e desenvolvimento da plântula de Amburana cearensis. A- Semente; B-G - Desenvolvimento da plântula; $\mathbf{H}$-da semente com detalhe dos cotilédones e eixo-embrionário; I - Semente com ala; al - ala - c - cotilédone; ca - catáfilo; cl - caule jovem; ep - epicótilo; ex - eixo-embrionário ; flfolha composta; fo - folíolo; h - hilo; hp - hipocótilo; $\mathbf{p}$ - pecíolo; pr - protófilo; rp- raiz primária; rs- raiz secundária; se - semente.

Figure 1 - Morphological aspects of Amburana cearensis seeds and seedlings A-Seed; B-G - seedlings development aspects;

$\boldsymbol{H}$ - Longitudinal section of seed showing the cotyledon and the axis-embryonic; $\boldsymbol{I}$ - seed with wing; $\boldsymbol{a}$ - wing; $\boldsymbol{c}$ - cotyledon; $\boldsymbol{c a}$-scale leaf; cl - stem couple; pe - epicotyl; ex-axis-embryonic; fl - Composed sheet; fo - foliole

$\boldsymbol{h}$ - hilum; hp - hypocotyl, $\boldsymbol{p}$ - petiole; $\boldsymbol{p r}$-foliage leaf; $\boldsymbol{r p}$-primary root, secondary root-rs; and se - seed. 
químicas para reativação do seu metabolismo. E a fase III, em que ocorre a protusão da raiz primária, foi verificada a partir das $84 \mathrm{~h}$ de embebição, caracterizando-se, assim, a germinação.

As sementes que não sofreram escarificação apresentaram retardamento no processo de embebição, não sendo possível diferenciar as fases I e II, sendo a fase III registrada a partir de $120 \mathrm{~h}$ de embebição. Nesse período, as sementes escarificadas apresentaram percentual alto de germinação, enquanto as sementes não escarificadas só exibiram elevado percentual de germinação a partir das 318 h de embebição. Pode-se constatar, assim, certo grau de impermeabilidade no tegumento das sementes de $A$. cearensis, no qual a escarificação facilitou a absorção de água, possibilitando a uniformidade do estande de germinação.

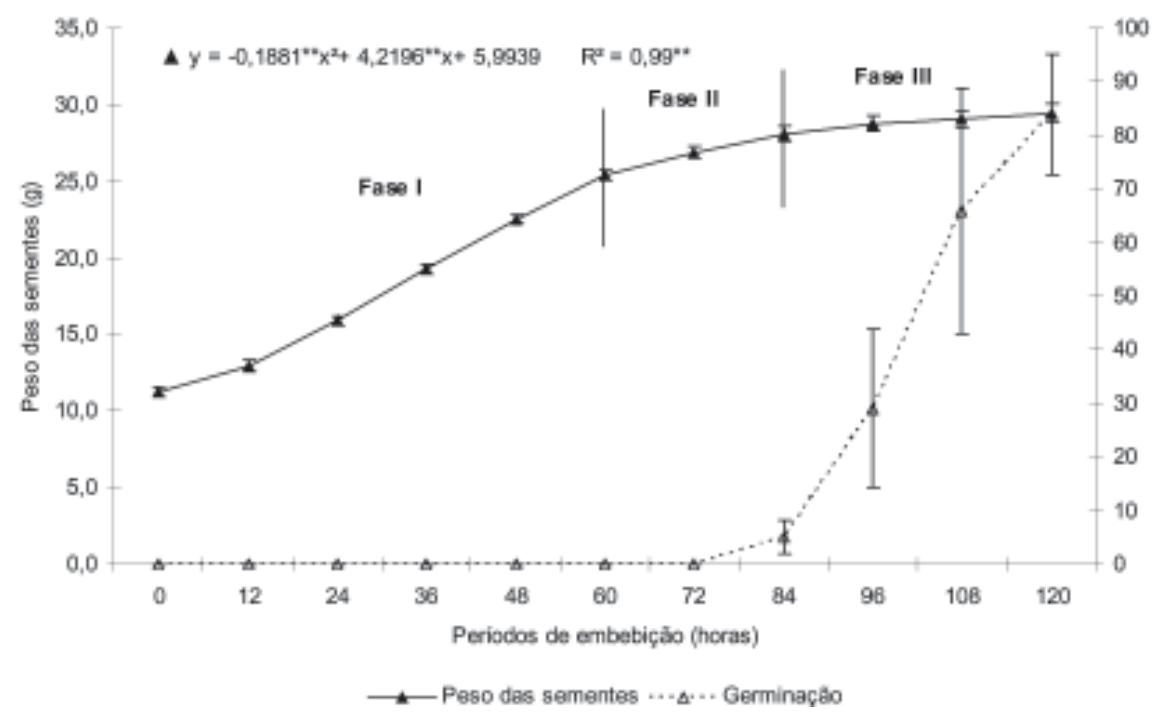

Figura 2 - Curva de absorção de água em sementes escarificadas de $A$. cearensis.

Figure 2 - Water absorption curve in A. cearensis scarified seeds.

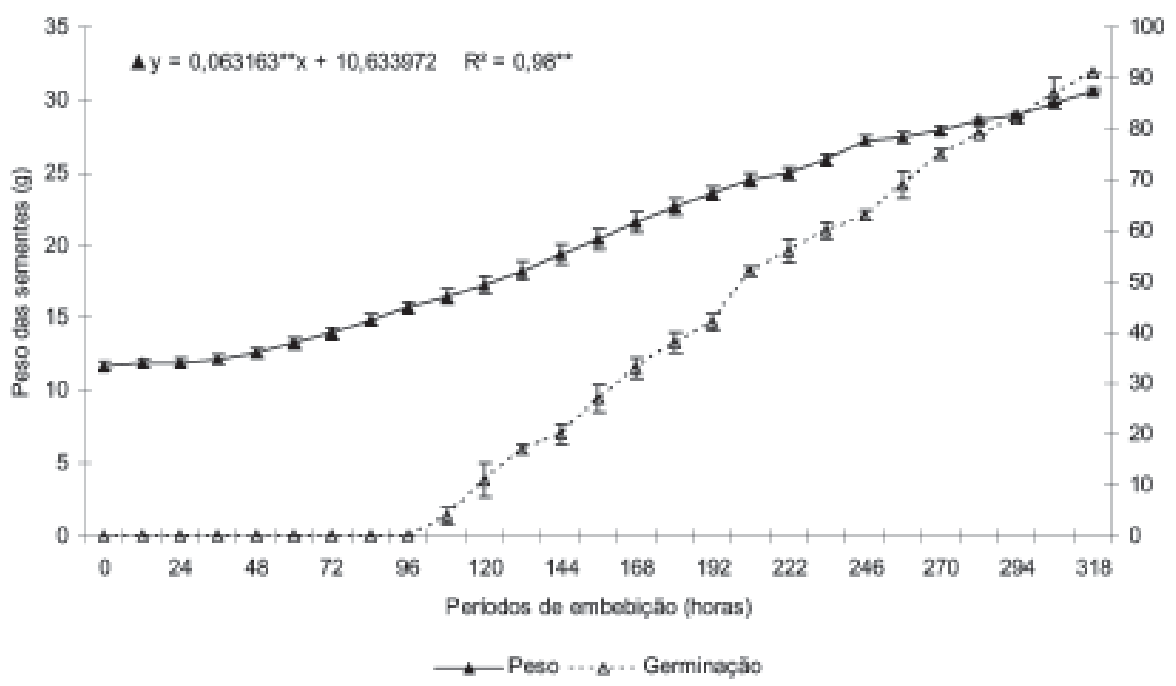

Figura 3 - Curva de absorção de água em sementes não escarificadas de $A$. cearensis.

Figure 3 - Water absorption curve in A. cearensis seeds.

Revista Árvore, Viçosa-MG, v.37, n.4, p.679-689, 2013 
A subfamília ceasalpinoideae apresenta uma variação quanto às características do tegumento das sementes. Lopes (2008) estudando a germinação de sementes de Dimorphandra wilsonii Rizz (Leguminosaecaesalpinioideae), verificou a presença de tegumentos impermeáveis a água, sendo que, as sementes escarificadas, após 70 horas de embebição apresentaram as diferentes fases da germinação, enquanto neste mesmo período, as sementes não escarificadas não apresentaram alteração alguma. Já Dantas et al. (2008) estudando a absorção de água em sementes de Caesalpinia pyramidalis (Leg-Caes.), não verificaram barreiras a absorção de água.

\subsection{Análise dos aspectos anatômicos durante a embebição de sementes de $A$. cearensis}

As sementes de $A$. cearensis apresentam dois tegumentos o externo, denominado exotesta e o interno, denominado tégmen, sendo classificada de acordo Apezzato-da-Glória e Carmello-Guerreiro (2003) como bitegumentada e exotestal, pois a exotesta representa o tecido com função mecânica na semente.

O tegumento é constituído por tecido esclerenquimático com três camadas, a primeira, mais externa, formada por um estrato de células alongadas, justapostas, esclerificadas, formando uma camada em paliçada rígida, com células denominadas macroesclereídes. A segunda camada é composta por um estrato de células colunares ou em forma de osso, denominada de osteoesclereídes, conforme definição de Esau (2000). A terceira camada localizada apenas na parte mais extrema da semente, próxima ao hilo, também é composta por osteoesclereides, com células mais arredondadas, levemente alongadas, paredes espessadas e grandes espaços intercelulares.

Na análise histoquímica pôde-se verificar a presença de compostos fenólicos na terceira camada, que juntamente com os osteoesclereídes podem ajudar a conferir impermeabilidade ao tegumento destas sementes (Figura 4I). Loureiro (2005) relatou a presença de substâncias fenólicas em sementes de Apuleia leiocarpa (Vogel) J.F. Macbr (Leguminosae - Caesalpinoidea), considerando esta característica como um dos fatores responsáveis pela impermeabilidade do tegumento das mesmas. Segundo Carvalho e Nakagawa (2000) existem sementes que são impermeáveis ao oxigênio, sendo que a restrição à entrada deste gás em seu interior é controlada basicamente pela presença de compostos fenólicos que ficam localizados nas camadas do tegumento.

$\mathrm{Na}$ região média da semente, a camada de osteoesclereides apresenta-se ligeiramente diferenciada, sendo formada por células mais longas e em menor quantidade (Figura $4 \mathrm{H}$ ).

$\mathrm{Na}$ (Figura 4D,E,F) estão representados as osteoesclereides em diferentes fases do processo de embebição. Pôde-se verificar que houve uma mudança na disposição das células, à medida que aumentaram os períodos de embebição, ocorrendo também um aumento no espaçamento entre as células a fím de facilitar a entrada de água na semente. Pôde-se verificar também que houve uma considerável redução dessa camada de células devido à expansão do embrião, o que fica mais visível nos períodos correspondentes à fase III (96 e 112 horas).

De acordo com Áquila (2004) na fase inicial do desenvolvimento todas as sementes possuem xenófito, ou endosperma, contudo, no transcorrer do desenvolvimento este pode ser completamente absorvido pelo embrião, estando essa estrutura presente na região basal da semente, local em que também ocorre a diferenciação dos osteoesclereides, sendo que em sementes maduras podem ocorrer até nove estratos de osteoesclereides, como em Senna macranthera (Leguminosa - Caesalpinoideae). Em A. cearensis através da observação dos tecidos da semente madura, pode-se verificar que ocorreu a diferenciação dos osteoesclereides, no entanto, não se pode confirmar a presença do xenófito, sendo necessário para tal um aprofundamento em estudos com relação à ontogenia da semente.

O tégmen é composto por uma camada de células, que segundo Apezzato-da-Glória e Carmello-Guerreiro (2003), em sementes exotestais não apresentam caracteristicamente especialização mecânica, pois em geral, são comprimidas pela expansão do embrião durante a maturação das sementes (Figura 4H). Mourão e Beltrati (1995), em estudo realizado com sementes de Platonia insignis Mart. (Clusiaceae) relatam que durante o desenvolvimento da semente, o tégmen apresenta entre 12 e 13 camadas celulares, sendo estas camadas reduzidas posteriormente, tornando-se o tégmen colapsado.

Os cotilédones são compostos por tecido parenquimático que apresenta características de reserva, este é formado por células isodiâmetricas, paredes

Revista Árvore, Viçosa-MG, v.37, n.4, p.679-689, 2013 
delgadas, numerosas pontuações e espaços intercelulares (Figura 4J). As células de revestimento dos cotilédones também são parenquimáticas, no entanto, com organização diferenciada, estando justapostas e formando uma camada unisseriada que reveste e delineia cada um dos cotilédones, separando-os.
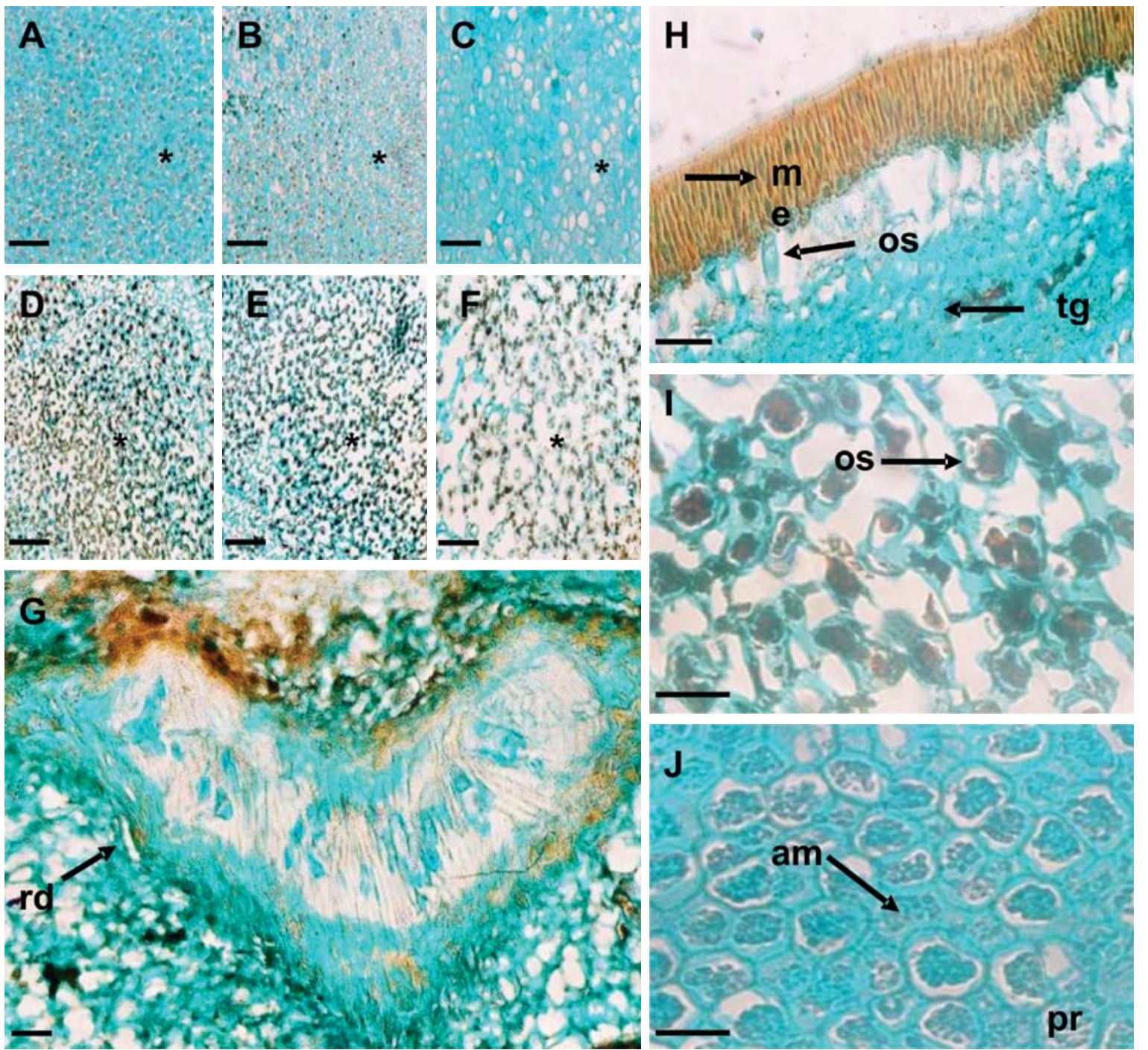

Figura 4 - Anatomia de sementes de Amburana cearensis em diferentes estádios de embebição. Seção Longitudinal. A-C - Concentração de grânulos de amido em diferentes períodos de embebição * $(0,24,96$ horas $)(0,92 \mu \mathrm{m})$; D-F aumento dos espaços intercelulares e redução da camada de osteoesclereides $(0,92 \mu \mathrm{m}) ; \mathbf{G}$ - radícula às 112 horas de embebição $(0,92 \mu \mathrm{m}) ; \mathbf{H}$-tegumento na região média da semente $(0,45 \mu \mathrm{m}) ; \mathbf{I}$-osteoesclereides às 0 horas $(0,22 \mu \mathrm{m})$; J -grânulos de amido no parênquima dos cotilédones $(0,22 \mu \mathrm{m})$; rd- radícula; me-macroesclereides; os- osteoesclereides; tg- tégmen; am- amido; pr-parênquima.

Figure 4-Anatomy of Amburana cearensis seeds in distinct imbibitions stages. Longitudinal section. A-C Changes in concentration of starch in different germination periods $*(0,24$ and 96 hours $)(0,92 \mu \mathrm{m}) ; \boldsymbol{D}-\boldsymbol{F}$ - intercellular spaces increase and osteoesclereides layer reduction $(0,92 \mu \mathrm{m}), \boldsymbol{G}$ - Radicle at 112 hours $(0,92 \mu \mathrm{m}) ; \boldsymbol{H}$-Seed coat in medial region, outer and inner testa details $(0,45 \mu \mathrm{m}), \boldsymbol{I}$ - osteoesclereides (0 hours) $(0,92 \mu \mathrm{m}), \boldsymbol{J}$ - Cotyledons parenchymatous fabric, starch granules $(0,92 \mu \mathrm{m})$. $\boldsymbol{r d}$-radicle; me - macroesclereids; os - osteoesclereids; $\boldsymbol{t g}$ - tegmen; $\mathbf{s t}$-starch; and pa-parenchyma.

Revista Árvore, Viçosa-MG, v.37, n.4, p.679-689, 2013 
Entre as células parenquimáticas encontram-se feixes vasculares, cuja função é transportar as substâncias de reserva deste tecido. Através de testes histoquímicos com lugol, pode-se verificar a presença de grãos de amido como principal reserva do tecido parenquimático.

Nas Figuras 4A, B e C estão representados os tecidos do parênquima que compõe os cotilédones. Comparando-se as três figuras, pode-se verificar que as células vão ficando mais túrgidas, e apresentam diminuição na concentração dos grânulos de amido durante a embebição das sementes. A partir de 24 horas de embebição ocorreu a diminuição dessa reserva, sendo os grânulos de amido não mais detectados. Uma provável justificativa para esta diminuição na concentração de amido seria a degradação e translocação desta reserva dos cotilédones para o eixo hipocótilo-radícula a fim de fornecer energia para o alongamento e crescimento celular durante a germinação das sementes. Uma outra alternativa seria a utilização deste amido como fonte de energia para o metabolismo das células do próprio cotilédone em expansão. De acordo Carvalho e Nakagawa (2000), os carboidratos servem como fonte de energia para a germinação da semente e o desenvolvimento das plântulas, mantendo processos metabólicos em funcionamento e/ ou como fonte de matéria para construção de tecidos vegetais que irão constituir a plântula.

Às 112 horas após o início da embebição foi verificado a expansão do embrião, com aumento do eixo e a protusão da radícula, período que corresponde a fase III do processo de embebição (Figura 4G).

As sementes de $A$. cearensis apresentam tegumento bastante resistente, devido a presença do tecido esclerenquimático, o que dificultou a rápida absorção de água e uniformidade na germinação. Melo-Pinna et al, (1999) em estudo com espécies da família Leguminosae, constataram que em Caesalpinioidea a camada paliçádica é responsável pela impermeabilidade do tegumento das sementes, o que também ocorre com A. cearensis havendo, portanto uma necessidade de escarificação das sementes a fim de promover uma maior uniformidade no estande final de plântulas.

Castillo e Guenni (2000) também associaram o nível elevado de dormência de Stylosanthes hamata (L.) Taub. (Leguminosae - Papilionoideae), a uma epiderme constituída por uma camada em paliçada, formada por macroesclereídes.

\section{CONCLUSÃO}

As sementes de $A$. cearensis são bitegumentadas, exotestais e a germinação é do tipo epígea e fanerocotiledonar. Quanto aos aspectos anatômicos a presença de macroesclereídes, osteoesclereídes e compostos fenólicos causam certo grau de impermeabilidade do tegumento, o que dificulta a absorção de água e confere as sementes uma dormência primária.

\section{REFERÊNCIAS}

APEZZATO-DA-GLÓRIA, B.; CARMELLOGUERREIRO, S. M. Anatomia vegetal.

Viçosa, MG: Universidade Federal de Viçosa, 2003. p.406-407.

AMORIM, I. L.; DADIVE, A. C.; CHAVES, M. M. F. Morfologia do fruto e da semente, e germinação da semente de Trema micrantha (L.) Revista Cerne, v.3, n.1, p.129-142, 1997.

ÁQUILA, M. E. A. Tipos de diásporos e suas origens. In: FERREIRA, A. G.; BORGHETTI, F. Germinação, do básico ao aplicado. Porto Alegre: Artmed, 2004. p.74, 79-80.

BARROSO, G. M. et al. Frutos e sementes: morfologia aplicada à sistemática de dicotiledôneas. Viçosa, MG: Universidade Federal de Viçosa, 1999. p.443.

BELTRATI, C. M. Morfologia e anatomia de sementes. Rio Claro: Universidade do Estadual de São Paulo/Instituto de Biociências, 1992. 108p.

BEWLEY, J. D.; BLACK, M. Seeds: physiology of development and germination. 2.ed. New York: Plenum Press, 1994. 445p.

BRASIL. Ministério da Agricultura e Reforma Agrária. Regras para análise de sementes. Brasília: SNDA/DNDV/CLAV, 1992. p.95-365.

CARVALHO, N. M.; NAKAGAWA, J. Sementes: ciência, tecnologia e produção. Jaboticabal: Funep, 2000. 588p.

Revista Árvore, Viçosa-MG, v.37, n.4, p.679-689, 2013 
CASTILLO, R.; GUENNI, O. Latencia en semillas de Stylosanthes hamata (Leguminosae) y su relación con la morfología de la cubierta seminal. Revista de Biología Tropical, v.49, n.1, p.287-299, 2001.

CANUTO, K. M.; SILVEIRA, E. R. Constituintes quimicos da casca do caule de Amburana cearensis A.C. SMITH. Quimica Nova, v.29, n.6, p.1241-1243, 2006.

CRESTANA, C. S. M. Recrutamento de plântulas de Genipa americana L. (Rubiaceae) em mata ripária. Revista Instituto Florestal, v. 10, n.1, p.1-15, 1998.

CUNHA, M. C. L.; FERREIRA, R. A. Aspectos morfológicos da semente e do desenvolvimento da planta jovem de Amburana cearensis (Arr. Cam.) A.C. Smith - Cumaru - Leguminosae Papilionoideae. Revista Brasileira de Sementes, v.25, n.2, p.89-96, 2003.

DANTAS, B. F.; CORREIA, J. S.; ARAGÃO, C. A. Alterações bioquímicas durante a embebição de sementes de Catingueira ( Caesalpinia pyramidalis Tul.). Revista Brasileira de Sementes, v.30, n.1, p.223-230, 2008.

DUCKE, J. A. Keys for the indentification of seedligs of some species in eight forst types in Puerto Rico. Annals of the Missouri Botany Garden, v.52, n.3, p.314-350, 1965.

DUCKE, J. A. On tropical tree seedlings, systems and systematics. Annals of Missouri Botanical Garden, v.56, n.2, p.135-161, 1969.

ESAU, K. Anatomia das plantas com sementes. São Paulo: Edgar Blucher, 2000. 293p.

GARCIA, L. C.; NOGUEIRA, A. C.; ALQUINI, Y. Aspectos morfo-anatômicos de sementes de Podocarpus lambertii Klotz. e

Podocarpus sellowii Klotz. - Podocarpaceae. Revista Brasileira de Sementes, v.28, n.3, p.129-130, 2006.

GUNN, C. R. Seed topography in the Fabaceae Seed Science \& Tecnology, v.9, n.3, p.737-757, 1981 .

Revista Árvore, Viçosa-MG, v.37, n.4, p.679-689, 2013
INTERNATIONAL UNION FOR CONSERVATION OF NATURE AND NATURAL RESOURCES. Iucn Red List. Disponível em: <http:// www.iucnredlist.org/>Acesso em: 09 out. 2008.

JULIO, P. G. S.; OLIVEIRA, D. M. T. Morfoanatomia e ontogênese do fruto e semente de Styrax camporum Pohl. (Styracaceae), espécie de cerrado do Estado de São Paulo. Revista Brasileira de Botânica, v.30, n.2, p.189-190, 2007.

KRAUS, E. J.; ARDUIN, M. Manual básico de métodos em morfologia vegetal. Seropédica: EDUR, 1997. 198p.

KUNIYOSHI, Y. S. Morfologia da semente e da germinação de 25 espécies arbóreas de uma floresta com araucária. 1983. 233 f. Dissertação (Mestrado em Engenharia Florestal); - Universidade Federal do Paraná. Curitiba, 1983.

LABORIAU, L. G.; VÁLIO, I. F. M.; HERINGER, E. P. Sobre o sistema reprodutivo de plantas dos cerrados. Anais da Academia Brasileira de Ciências, v.36, n.4, p.449-464, 1964.

LOPES, J. C.; MATHEUS, M. T. Caracterização morfológica de sementes, plântulas e da germinação de Dimorphandra wilsonni Rizz, faveiro-de-wilson (Fabaceae-caesalpinioideae). Revista Brasileira de Sementes, v.30, n.1, p.98, 2008.

LORENZI, H. Árvores brasileiras: manual de identificação e cultivo de plantas arbóreas nativas do Brasil. Nova Odessa: Plantarium, 1992. 352p.

LOUREIRO, M. B. Conservação de sementes de Apuleia leiocarpa (Vogel) J.F. Macbr.- Garapa (Leguminosae Caesalpinoideae). 2005. 51f. Tese (Doutorado em Fitotecnia) - Instituto de Pós-graduação Fitotecnia, Seropédica, 2005.

MELO-PINA, G. F. A.; NEIVA, M. S. M.; BARBOSA, D. C. A. Estrutura do tegumento seminal de quatro espécies de Leguminosae (Caesalpinoidea), ocorrentes numa área da caatinga (PE Brasil). Revista Brasileira de Botânica, . 22, n. 3, p. 375-379, 1999. 
MELO, M. G. G.; MENDONÇA, M. S.; MENDES, A. M. S. Análise morfológica de sementes, germinação e plântulas de jatobá (hymenaea intermedia ducke var. adenotricha leguminosas forrageiras tropicais. Campo Grande, MS: (ducke) lee \& lang.) (Leguminosae-caesalpinioideae). Acta Amazônica, v.34, n.1, p.9-14, 2004.

MENDONÇA, M. S. et al. Morfo-anatomia do fruto e semente de Oenocarpus minor Mart. (ARECACEAE). Revista Brasileira de Sementes, v.30, n.1, p.91-98, 2008.

MIQUEL, S. Morphologie, fonctionnelle de plantules d'éspèces forestières du Gabon. Bulletin du Muséum Nacional D'Histoire Naturelle, v.9, n.1, p.102-120, 1987.

MOURÃO, K S.; BELTRATI, C. M. Morfologia dos frutos, sementes e plântulas de Platonia insignis MART. (CLUSIACEAE). I. Aspectos anatômicos dos frutos e sementes em desenvolvimento. Acta Amazônica, v.25, n.1, p.11-32, 1995.

OLIVEIRA, D. M. T. Morfo-anatomia do embrião de leguminosas arbóreas nativas. Revista Brasileira de Botânica, v.22, n.3, p.413-427, 1999.

OLIVEIRA, D. M. T. Morfologia comparada de plântulas e plantas jovens de leguminosas em arbóreas nativas: espécies de Phaseoleae, Sophoreae, Swartzieae e Tephrosieae. Revista Brasileira de Botânica, v.24, n.1, p.85-97, 2001.
OLIVEIRA, E. C. Morfologia de plântulas florestais. In: AGUIAR, I. B.; PIÑA-RODRIGUES, F. C. M.; FIGLIOLIA, M. B. Sementes florestais tropicais. Brasília: Abrates, 1993. p.175-214.

RADFORD, A. E. et al. Vascular plants systematics. New York: Harper \& Row, 1974. $877 \mathrm{p}$.

RAVEN, P. H.; EVERT, R. F.; EICHHORN, S. E. Biology of plants. 6.ed. New York: W. H. Freeman and Company, 1999.

RENÓ, L. R.; MOSCHETA, I. S.; BRACCINI, A. L. Morfo-anatomia do fruto e semente de amarelinho (Tecoma stans (L.) Kunth - Bignoniaceae).

Revista Brasileira de Sementes, v.29, n.3, p. $18-30,2007$

RIZZINI, C. T. Estudos preliminares sobre o xilopódio e outros órgãos tuberosos de plantas do cerrado. Anais da Academia

Brasileira de Ciências, v.37, n.1, p.87-113, 1965.

SOUZA, F. H. D.; MARCOS-FILHO, J. The seed coat as a modulator of seed-enviroment relationships in Fabaceae. Revista Brasileira de Botânica, v.24, n.4. p.1-16, 2001.

STERN, W. T. Botanical latin. History, grammar, syntax, terminology and vocabulary. New York: Hafner Publishing Company, 1992. $566 \mathrm{p}$. 
